\title{
Impact of COVID-19 on the Global Tourism Industry and Ways to Ensure High Competitiveness of the Territory in the Global Tourism Market after the Pandemic
}

\author{
Vadim Pashkus ${ }^{1, *}$, Natalia Pashkus $^{2}$, Asadula Asadulaev ${ }^{1}$ \\ ${ }^{1}$ Saint Petersburg State University, Faculty of Economics, Department of Economics \& Economic \\ Policy, University embankment 7-9, 199034, St Petersburg, Russia \\ ${ }^{2}$ Herzen State Pedagogical University, Institute of Economics and Management, Department of \\ Industrial Economics and Finance, the Moika river emb., 48.St. Petersburg, Russia
}

\begin{abstract}
.
Research background: The article analyzes the impact of the COVID-19 pandemic on the tourist competitiveness of St. Petersburg. In order to maintain sustainable tourist attractiveness after the end of the pandemic, the city will have to conduct a more thorough analysis of the factors influencing the choice of St. Petersburg among other competing tourist centres.

Purpose of the article: The purpose of this article is to identify competitive priorities of territories that are attractive for tourism activities in the conditions of recovery from the crisis that arose due to restrictive measures applied due to the coronavirus pandemic.

Methods: To achieve this goal, the article uses a modified SWOT analysis apparatus with the use of a matrix assessment methodology implemented on the basis of a modified methodology of the Hierarchy Analysis Method and the calculation of marginal replacement coefficients for criteria of tourist attractiveness and competitiveness of the territory after the pandemic.

Findings \& Value added: For the analysis, a new approach is proposed to obtain the characteristics of the city assessment for different categories of tourists, which significantly increases the accuracy and strategic prospects of the classical procedure of SWOT analysis. As a scientific growth, we can consider the use of matrix estimation mechanisms for a more rational ranking of factors, more accurately determining probability and weight characteristics. Therefore, this will provide higher accuracy of strategic recommendations for the city for each important category of tourists.
\end{abstract}

Keywords: Global Tourism Industry; Competitiveness of the Territory; SWOT analysis; Hierarchy Analysis Method

JEL Classification: $L 83$

\footnotetext{
* Corresponding author: v.pashkus@spbu.ru
} 


\section{Introduction}

The global economy is known to be dominated by services and intangible assets. Therefore, we should not be surprised that, as emphasized by Steven Pike and Dani Rodrik, the tourism sector is one of the engines of growth of the modern economy [1,2]. Therefore, today, in the context of the global crisis caused by the development of the coronavirus pandemic, there is a serious problem of maintaining the tourist attractiveness of countries and cities. It can be noted that those territories that have created a developed myth that underlies a strong brand will benefit the most [3]. After the end of the pandemic, only cities with a strong global brand will be able to ensure a rapid recovery of the tourist flow $[4,5]$. On the one hand, people in all countries are exhausted by forced seclusion and will welcome the resumption of travel opportunities. They will want to come back to their favorite places. On the other hand, as long as there is the slightest risk of infection, strict rules will apply, both for those leaving the country and for those entering it. There may be requirements for confirmation of the fact of safety of the tourist's stay in the country, which is quite difficult from a legal, medical and customs point of view. In addition, even a confirmed past case of illness and recovery cannot yet confirm that a person is safe in terms of potential transmission of the disease. Since different countries have recorded different strains of the virus, and the virus can mutate further, which will lead to infecting already ill with one type of human infection with the others, so he again can be potentially dangerous.

But the main problem with the resumption of global tourist flows will be associated with a sharp reduction in the income of citizens in countries suffering from the development of the pandemic. These are also the countries where the pandemic is severe, and a large number of cases and deaths are registered. As well as those countries that themselves are less affected by the rampant virus, but whose economy is tied to tourism activities or participation in global economic alliances. Thus, these are virtually all economically developed countries whose population actively traveled and where the tourism industry was actively functioning. As a result of the economic crisis, there was a significant drop in the income of a significant part of the population, and first of all, the income of residents of the largest cities, which previously formed the basis of the tourist flow from these countries, was affected. Similarly, the owners of the tourist business or all structural divisions of the tourist infrastructure, experiencing economic problems, will not be able to restore the operation of their enterprises quickly enough, and may try to "catch up" and inflate the prices for their services, primarily for foreign tourists. All this may hit the tourist infrastructure of the countries again, as it will cause a new decline in tourist flows.

Therefore, it is necessary to develop an effective strategy in advance to develop and strengthen the brand of the territories of their countries in order to influence the tourist attractiveness of the most promising cities for the most attractive target audiences even during the pandemic. Moreover, it is necessary to take a number of measures of state regulation and support of the industry in order to avoid possible overpricing and unreasonable requirements for foreign tourists. This will help to avoid a secondary crisis in the tourism industry, and possibly change global tourism trends in favor of their territories.

\section{Methodology}

To study the factors that are most important for the implementation of an effective strategy for the development and strengthening of Russia's tourist attractiveness, we will consider the possibility of using SWOT analysis tools for various target groups. Moreover, due to the high degree of error of the SWOT analysis method, we can propose a new modification of this 
procedure that uses matrix algorithms and methods for evaluating marginal replacement coefficients for each of the considered criteria for evaluating a territory or its brand.

We will select the territory of Saint Petersburg for analysis, as a city that, on the one hand, has a strong cultural brand and is most in demand by a significant share of foreign tourists. On the other hand, a city that has a significantly lower budget than Moscow and is not able to provide adequate support to the city's tourism industry and related areas of activity, primarily in the field of culture, public catering, hotel cluster, etc., without the use of funds from the Federal center. The choice of Saint Petersburg with its cultural orientation of the brand is determined by the fact that Russia as a whole is not able, due to climatic reasons, to offer foreign tourists comfortable conditions for a classic beach holiday, chosen by a significant proportion of tourists. Therefore, it makes sense for Russia to rely on the development and promotion of its cultural identity and improving the attributes of cultural brands of cities that dominate the cultural space. Moreover, the developed tourism sector leads to a clear multiplier effect, stimulates economic growth and fits the policy of import substitution $[6,7]$.

Let's look at the most important target audiences of foreign tourists, which are targeted by the city's cultural brand, and which should be covered by measures aimed at maintaining and developing the city's cultural brand. These are mainly three large target groups. First, they are tourists from South-East Asia (SE), mainly tourists from China, South Korea, and Japan. Secondly, they are tourists from Europe. In particular, from the following countries: Italy, Germany, France, Great Britain, Sweden and Finland. However, tourists from Finland are most often focused on slightly different characteristics of the city's brand. A significant proportion of Finns who come to the city are more likely to be shop tourists or tourists who want to "have fun", betting on alcohol that is more affordable in relation to Finland. Therefore, no more than a third of this category are consumers of the city's cultural brand.

We should also mention the third large-scale target audience of foreign tourists-US citizens. This target group is largely made up of cruise tourists who have the right to spend 72 hours in the city without a visa. Other American tourists come to Russia and the city for a longer period than other tourists. In recent years, however, there have been some problems with strained political relations with the United States, as well as mutual problems with the provision of visas, but these problems have not significantly affected the fall in tourist flows from the United States. There are other large target groups of foreign tourists in the city, for example, tourists from India, Canada, Latin America, whose appearance in the city is associated with the last world Cup. However, the share of these tourists before the development of the pandemic was still not high, and for a significant part of these countries, travel to Russia is very expensive due to the long distances, and the level of income in these countries on average was lower before the development of the pandemic. Therefore, it is necessary to focus on three target groups of foreign tourists and study the factors that contribute to the attractiveness of the city for them. In this article, we will consider only one of the most significant consumer groups that many cities and countries have been betting on in recent years in the development of inbound tourism, namely, a group of tourists from Southeast Asian countries with an emphasis on Chinese citizens. This group has unique characteristics $[8,9]$ and it is one of the dominant ones in the market of St. Petersburg.

So, the largest target group of foreign tourists in St. Petersburg is tourists from Southeast Asian countries, among which Chinese citizens predominate. For this reason, it is necessary to take into account the significant contribution of the interests of this category of tourists when selecting the characteristics of St. Petersburg according to the SWOT analysis procedure. Initially, it is necessary to identify the main competitors of the city in the global tourism market. Notable among them are the following cities that are most in demand by tourists from Southeast Asia and, in particular, the citizens of China: 

1. Paris
5. Venice
2. Florence
6. Moscow
3. London
7. Milan
4. Prague
8. Rome

These cities have a strong cultural orientation of the brand, formed tourist infrastructure and developed tourist attractiveness. All competing cities are focused on a significant share of the inflow of tourism revenues to the city budget. All competing cities have cultural brand attributes that are close to Saint Petersburg. So, we can consider the following characteristics of St. Petersburg using the SWOT analysis method in terms of the city's attractiveness for tourists from Southeast Asian countries (see table 1).

Table 1. SWOT analysis of Saint Petersburg for tourists from Southeast Asia

\section{Strength:}

1. Established tourist infrastructure and a developed system of rounds: 3

2. Affordable prices, particularly for accommodation and sightseeing: 3

3. Economic partnership with China and other Southeast Asian countries, close relationship: 4

4. Brand of white nights and cultural festivals during the white nights period: 5

5. Transport accessibility in the city, accessibility of attractions: 2

6. Information signs and electronic tourist applications in Chinese and other languages of Southeast Asian countries: 2

7. Availability of public catering organizations with South-Eastern cuisine, high-quality natural products: 4

8. Payment systems that are widely used in Southeast Asian countries: 3

9. Developed Chinese Diaspora and cultural diasporas of other Southeast Asian countries: 5

10. Richness and diversity of culture, art museums and galleries: 5

11. Variety of architectural and landscape ensembles: 5

12. Strong brands of cultural organizations: 5

13. Strong brand of Russian ballet: 5

\section{Opportunities:}

1. Development of project activities, initiation of major international congresses, festivals and other events, in particular to boost tourism activity in the autumn-winter period: $0.5 ; 0.7$

2. Development of the city's transport system: $0.4 ; 0.6$

3. Development of international exchange programs with Southeast Asian countries in various fields: $0.8 ; 0.7$

\section{Weakness:}

1. Negative climate and seasonality of tourist flow: -4

2. The city's transport system is Not efficient enough: -3

3. High prices for direct flights: -3

4. Illegal segment of the tourist business and fraud against tourists: -5

5. Negative attitude towards the Chinese and citizens of Southeast Asian countries in the city's population: -2

6. Poor preservation and slow restoration of monuments and buildings in the tourist part of the city: -4

7. Insufficient number of free cultural places: -3

\section{Threats:}

1. Deterioration of political relations with China and other Southeast Asian countries: $0.2 ; 0.8$

2. Development of global crises, pandemics and other catastrophic situations that prevent movement between countries and joint economic activities: $0.6 ; 0.9$

3. Decrease in the purchasing power of the population of Southeast Asian countries: $0.5 ; 0.8$ 
4. Improvement of the regulatory framework for tourism activities and development of the system of control over the work of enterprises in tourism and related industries: 0,$4 ; 0,8$

5. Development of anti-corruption measures in the field of international exchange and tourism: $0.3 ; 0.9$

6. Urban infrastructure Development: 0.6;0.7

7. Development of information coverage of the city's activities and implementation of promotion projects on electronic resources of Southeast Asian countries: $0.7 ; 0.9$

8. Development of cultural and educational projects and online programs in Chinese and the languages of Southeast Asian countries, in particular with the provision of double diplomas: $0.5 ; 0.7$

9. Promotion of Russian food products in China and other Southeast Asian countries, implementation of sampling programs: 0.7 ; 0.7
4. Decrease in the quality of tourist support and efficiency of the tourism industry, as well as deterioration in the quality of products produced in Russia due to the economic crisis: $0.6 ; 0.8$

5. Mass infobrosses and information posters that create obstacles to interaction and transmission of objective information about the city and its projects: 0,$4 ; 0,7$

6. Deterioration of relations with tourists from Southeast Asian countries on the part of residents of St. Petersburg: 0.4; 0.7

The SWOT analysis method will help determine the most significant characteristics of a city that affect its priority choice by this category of consumers among other competing cities. In accordance with this procedure, it is assumed to apply expert analysis and assign each characteristic of the city a rating on a scale from 1 to 5 for strengths, similar to negative ratings for weaknesses, and two estimates of the influence coefficient and probability, set in the range from 0 to 1 for opportunities and threats. However, due to the large number of parameters and the complexity of comparing the characteristics of the city with the characteristics of its competitors, it is advisable to assess the competitive position of the city using the hierarchy analysis method modified by the authors. In particular, the most important competitive characteristics of the city should be evaluated by pairwise comparison of St. Petersburg with competitors for each characteristic, which will significantly improve the accuracy of estimates. When analyzing opportunities and threats, probabilities can be estimated using stochastic procedures, and estimates of influence coefficients can be obtained using modified MAI methods, performing pairwise comparisons of the strength of the impact of all opportunities and threats on the attractiveness of St. Petersburg for tourists from Southeast Asia.

Using the modified MAI procedure, we obtain normalized weight coefficients that will allow us to weigh the competitive position of the city in relation to its main competitors and, thus, compare competitors. Using the scale of the modified MAI procedure, we form a matrix of dimension $\mathrm{n}$ corresponding to the number of analyzed cities:

$$
\left(\begin{array}{ccc}
a_{11} & \ldots & a_{1 n} \\
\ldots & \ldots & \ldots \\
a_{n 1} & \ldots & a_{n n}
\end{array}\right)
$$

Then you can find: 


$$
\begin{aligned}
& A_{1}=\sqrt[n]{a_{11} \cdot a_{12} \cdot \ldots \cdot a_{1 n}} \\
& A_{2}=\sqrt[n]{a_{21} \cdot a_{22} \cdot \ldots \cdot a_{2 n}} \\
& \ldots \ldots \ldots \ldots \ldots \ldots \ldots \ldots \ldots \ldots \ldots \ldots \ldots \ldots \ldots \ldots \ldots \ldots \\
& A_{n}=\sqrt[n]{a_{n 1} \cdot a_{n 2} \cdot \ldots \cdot a_{n n}}
\end{aligned}
$$

Then the priority vector will be evaluated as follows:

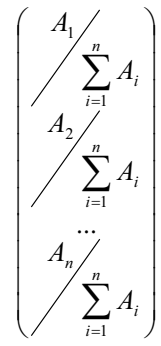

\section{Results}

The analysis of the strengths of St. Petersburg for the selected target group of consumers in comparison with competing cities allowed us to evaluate the potential of the city using the modified MAI procedure and identify its position in the global brand competition (see Fig. $1)$.

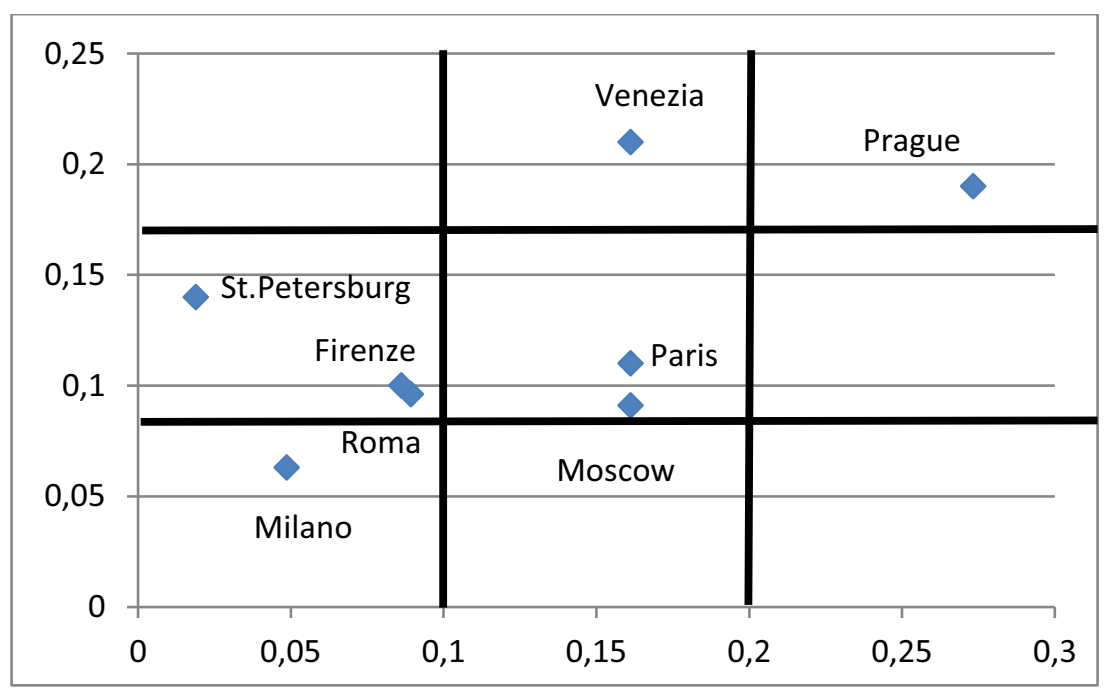

Fig. 1. Competitive positions of competing cities for tourists from Southeast Asian countries with priority for Chinese tourists.

The most dangerous, from a competitive point of view, position in the current post-crisis period is occupied by Milan and Rome in second place, which fall into the area of maximum risk, which is realized due to the high level of influence of threats and the lack of consideration of existing opportunities to increase the attractiveness of the city for this category of tourists. Given that Milan's economy was hit the hardest during the Italian pandemic, and it is likely that it will not be able to properly prepare for the new demands from the global tourism market, the city may experience serious problems when opening 
borders and resuming tourist flows. There may be problems with a sharp decline in the analyzed category of tourists in Rome. In a slightly better position is Florence, which recently attracted huge tourist flows, including from the analyzed countries. At the same time, the infrastructure of Florence has long been unable to cope with the existing volumes of tourists, which caused an increase in prices for accommodation, visits to tourist sites, transport, Parking, Souvenirs, etc. This created additional difficulties for tourists when visiting the city, including tourists from the group of countries under consideration.

Saint Petersburg's competitive position is somewhat better, although the city is in the same high-risk position as Rome and Florence. However, the position of St. Petersburg is characterized by a certain weakness in relation to these cities, but a higher potential. Therefore, by taking into account new opportunities and leveling threats, the city can improve its position for the analyzed category of tourists. Among the threats, the city should pay the greatest attention to the potential decline in the quality of tourist support and the efficiency of the tourism industry. This is possible due to reduced public spending on culture and the restoration of cultural heritage sites, as well as due to the overall reduction in the city's budget and its inability to implement previously planned infrastructure projects, and stagnation of further development. There are already some negative trends in this direction. So, the city postponed the implementation of transport reform, which is true, there are positive aspects, since the quality of thoughtfulness and preparation of this reform left much to be desired. The development of the road network and the expansion of the metro, which had previously developed very slowly, also slowed down. This negative trend can significantly worsen the competitive position of the city.

Another factor that the city needs to pay attention to is the possibility of deterioration in the quality of products produced in Russia, many of which are produced in St. Petersburg and the Leningrad region, or are delivered to the city from other regions of Russia. Here we can state a rather positive situation in the city: during the peak of the pandemic and subsequent periods, food supplies from a number of regions of Russia have significantly expanded,which makes it possible to fully provide the city with high-quality domestic products. This increases the future attractiveness of the city for foreign tourists, especially for tourists from Southeast Asian countries. Moreover, despite the climatic conditions, St. Petersburg did not lose its position in the production of agricultural products, expanded the range and improved the quality of the food industry.

There is also the problem of mass infobrosses and information blockages that create obstacles to interaction and transmission of objective information about the city and its projects. The period of the pandemic and the territorial division of countries, and even regions of one country, has shown that this threat is not just real, but very dangerous. The massive transition to digital technologies in many sectors of the economy has also revealed the positive effects of the pandemic, which are associated with the fact that the forced withdrawal to the digital space has forced industries to adapt better and faster to new conditions. Where previously the transition to digital technologies was discussed and postponed, in an emergency situation it occurred, although problematic, but quickly. Specialists in various fields have gained a completely new experience that will be developed in the future. However, territorial disunity has also allowed information wars to be carried out, speculating on human fears, distrust and the General tense situation. There is a huge amount of news that is very similar to the truth, negatively representing the situation in Russia as a whole, and can negatively affect the brand of St. Petersburg and its attractiveness to various categories of tourists, including the analyzed one. The General "nervous" situation in the world, economic and political instability, can very much hurt the tourist reputation of the city. Thus, despite budget cuts, during this period the city should make even more efforts to develop and 
strengthen its brand, which in the future will be able to provide it with high tourist attractiveness.

Moscow and Paris are in the most average risk group. Paris has a more stable and strong brand in relation to Moscow. But in the current situation, the pandemic has shown the inability to keep the situation under control, the growth of unrest and the aggravation of political processes. The inability to cope with the pandemic and political unrest has had a very negative impact on the economic situation in France in General, and in Paris in particular. So given that the city's future attractiveness is based on the strength and sustainability of its brand, Paris ' position in the global tourism market is ambiguous. At the same time, the risk level of this competitor for the selected target group of consumers is generally lower than that of the previously considered cities. In recent years, Moscow has attracted more and more tourists due to the city's competent cultural and infrastructure policy, as well as a number of measures to develop the city's brand. However, the General wary attitude towards Russia in the world and the direct mental connection of the country's policy with its capital, cause both a certain surprise and even delight in relation to the city, and the growth of false fears and other negative effects. For Moscow, even more than for Saint Petersburg, it is important to form a strong, sustainable brand of the city and protect it from the influence of infowalls. The peculiarity of the position that Moscow and Paris got into is that from this position it is possible to move up and to the right in the direction of leadership, as well as to fall to the lower left positions of maximum risk and lower competitive status.

The last two competitors of Saint Petersburg remain: Prague, which is in the leading position,and Venice, which is in the low-risk area of a strong competitor. Venice provides the current strong competitive position due to a very high level of brand development. In fact, Venice has the strongest branded appearance, forming $100 \%$ recognition of the city. Therefore, the attractiveness of the city to visit remains the maximum. Moreover, people who are tired of everyday life and isolation in their country, first of all, will rush again or finally see what everyone knows and will be able to appreciate in the information space. As it does not look banal, but a beautiful photo on a well-known background solves everything.

Prague, the least affected in Europe by the pandemic. Prague's global brand is also very strong, as are its branded types. Prague is not associated with any serious political conflicts or disasters. The city, of course, also suffers huge losses from the lack of tourist flow from the Southeast Asian countries, and other countries, as well as other European cities, but so far these problems do not go beyond Prague, well, at least in terms of information. All this will allow the city to remain an attractive destination for tourists from Southeast Asian countries in the future.

\section{Discussion}

The model of city competition proposed by the authors can be useful for a detailed study of competitive positions and will complement the existing methods of SWOT analysis, which are also not fully and in detail used in territorial marketing and the development of the tourism industry. However, there are a number of problems associated with its use.

First, the factors influencing the SWOT analysis were considered in relation to the" average " tourist flow. However, different tourist clusters are currently being studied, which change the attractiveness of destinations. New directions include creative tourism, which significantly changes the situation on the market $[10,11]$, ecotourism that changes the usual criteria for the competitiveness of tourist destinations $[12,13]$. We also note the growth of cultural tourism, which is a kind of response to the strong cultural brand of the territory [3, 14]. The conditions of tourist activity themselves are also changing (for example, the phenomenon of Shared accommodation $[15,16,17])$, the seasonality [18] is changing and a 
number of significant factors of demand for global tourism are emerging [19] as well as crucial social changes $[20,21]$.

Secondly, this model does not take into account the capabilities and strength of the territory's brand. At the same time, such branding luminaries as Simon Anholt, Philip Kotler and David Gertner write about the need to develop the territory's brand [20,21]. The correct perception of the image can lead to a sharp increase in tourist flows, which is especially noticeable with the correct state policy aimed at supporting tourism [22, 23, 24].

Thus, making certain adjustments makes this model a useful tool that will allow you to consider the competitiveness of territories.

\section{Conclusion}

So, the analysis showed that the pandemic hit the global tourism industry very hard, and caused many negative effects that will affect the global attractiveness of cities in the future. On the example of the selected target group of consumers of tourists from Southeast Asian countries and, above all, residents of China, it is clear that the consequences of the pandemic for traditionally attractive cities for this category of tourists are huge. The pandemic is causing significant changes in the competitive situation in the tourism market. As a result, a realignment of the tourist market has been launched, during which each competitor must clearly understand which factors they should pay the most attention to, since they determine the choice of consumers.

\section{Reference}

1. Rodrik, D. (2018). Populism and the Economics of Globalization. Journal of international business policy, 1(1-2), 12-33.

2. Pike, St. (2008). Destination Marketing: An Integrated Marketing Communication Approach. Oxford: Butterworth-Heinemann.

3. Pashkus, N.A. et al. (2019) Cultural City Brands and Global Competitiveness. Revista San Gregorio, 36, 197-209.

4. Pellesova, P. (2020). Globalization and perception of tourism trends by supply and demand. SHS Web of Conferences, 74, 04019.

5. Onder, I. (2017). Forecasting Tourism Demand with Google Trends: Accuracy Comparison of Countries versus Cities. International Journal of Tourism Research, 19(6), 648-660

6. Pellesova, P. (2015). Tourism and multiplication effents in the region. In: Innovation managament and sustainable economic competitive advantage: from regional development to global drowth, volsi - VI. Madrid: Int Business Informat Managament Assoc, s. 515-520.

7. Aliaskarova, Z., Pashkus, V., \& Blagikh, I. (2020). Proactive industrial policy as the main strategy for improving Russia's competitiveness in the context of global economic processes. In SHS Web of Conferences, 74, 06002.

8. Hall, C.M., Page, S.J. (2017) The Routledge Handbook of Tourism in Asia. Abingdon: Routledge.

9. Bolotin, Yu. E., Sanzharova, G.D. (2020). Development of Internal Tourism in Russia: Statistics and Perspectives. Problems of the modern economy, 1(73), 162-166. 
10. Tan, S. K., Luh, D. B., \& Kung, S. F. (2014). A taxonomy of creative tourists in creative tourism. Tourism Management, 42, 248-259.

11. Chang, L-L., Backman, K.F., Huang, Y.C. (2014). Creative tourism: a preliminary examination of creative tourists' motivation, experience, perceived value and revisit intention. International Journal of Culture, Tourism and Hospitality Research, 8(4), 401-419.

12. Alpopi, C., Diaconu, S., Velicu, E.R. (2020). Strategies on the development of ecotourism at the Bucharest in the context of globalization. SHS Web of Conferences, 74, 05003

13. Bowen, J., Whalen, E. (2017). Trends that are Changing Travel and Tourism. Worldwide Hospitality and Tourism Themes, 9(6), 592-602

14. Richards, G. (2018). Cultural tourism: A review of recent research and trends. Journal of Hospitality and Tourism Management. Journal of Hospitality and Tourism Management, 36, 12-21

15. Kostkova, M. (2020). Shared accommodation as a globalization trend in tourism. SHS Web of Conferences, 74, 03002

16. Xu, F., La, L., Zhen, F., Lobsang, T., \& Huang, C. (2019). A data-driven approach to guest experiences and satisfaction in sharing. Journal of Travel \& Tourism Marketing, 36(4), 484-496.

17. Hollowell, J. C., Rowland, Z., Kliestik, T., Kliestikova, J., \& Dengov, V. V. (2019). Customer loyalty in the sharing economy platforms: how digital personal reputation and feedback systems facilitate interaction and trust between strangers. Journal of SelfGovernance and Management Economics, 7(1), 13-18.

18. Duro, J. A. (2018). Seasonality of tourism: A new decomposition. Tourism economics, 24(5), 615-621.

19. Claveria, O., Monte, E., Torra, S. (2015). Common trends in international tourism demand: Are they useful to improve tourism predictions? Tourism Management Perspectives, 16, 116-122

20. Kliestik, T., Misankova, M., Valaskova, K., Svabova, L. (2018). Bankruptcy prevention: new effort to reflect on legal and social changes. Science and Engineering Ethics, 24(2), 791-803.

21. Meluzin, T., Zinecker, M., Balcezrak, A.P. Doubravsky, K., Pietrzak, M.B., Dohnal, M. (2018). The timing of initial public offerings - non-numerical model based on qualitative trends. Journal pf Business Economics and Management, 19(1), 63-79.

22. Anholt, S. (2007). Competitive Identity: The New Brand Management for Nations, Cities and Regions. London: Palgrave Macmillan.

23. Kotler, P., Gertner, D. (2002). Country as brand, product, and beyond: a place marketing and brand management perspective. Journal of Brand Management, 9(4), 249-261.

24. Buhalis, D. et. al. (2018). A model of perceived image, memorable tourism experiences and revisit intention. Journal of Destination Marketing \& Management, 8, 326-336

25. Foroudi, P., Gupta, S., Kitchen, P., Foroudi, M. M., \& Nguyen, B. (2016). A framework of place branding, place image, and place reputation. Qualitative Market Research: An International Journal, 19(2), 241-264.

26. Pashkus, V. Y., Pashkus, N. A., \& Pashkus, M. V. (2016). Evaluation of City Brand in the Global Economy: Techniques and Perspectives. In Globalization and its SocioEconomic Consequences, 1635-1641. 